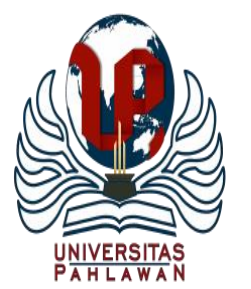

Jurnal Abdidas Volume 1 Nomor 5 Tahun 2020 Halaman 471 - 477

JURNAL ABDIDAS

http://abdidas.org/index.php/abdidas

\title{
Pelatihan Penggunaan Mesin Roasting Modern dalam Pengelolaan Kopi Arabika pada Kelompok Swadaya Masyarakat Galuh Lestari
}

\author{
Ria Manurung1, Oskar Ika Adi Nugroho ${ }^{2}$, Eko Apriliyanto ${ }^{3}$ \\ Sekolah Tinggi Ilmu Komputer Yos Sudarso, Jawa Tengah, Indonesia ${ }^{1,2}$ \\ Politeknik Banjarnegara, Jawa Tengah, Indonesia ${ }^{3}$ \\ E-mail : ria.manurung@ stikomyos.ac.id ${ }^{1}$ oskar@stikomyos.ac.id ${ }^{2}$ okeapriliyanto@gmail.com ${ }^{3}$
}

\begin{abstract}
Abstrak
Proses produksi roasting kopi arabika KSM Galuh Lestari masih manual dengan peralatan sederhana berupa tabung drum. Hasil dari proses roasting secara manual tersebut tidak merata tingkat kematangan dan warna kopinya, membutuhkan waktu yang lama dan tingkat kehati-hatian yang sangat tinggi dalam proses roasting kopi produksinya. Penyimpanan produk kopi belum memadai. Solusi dari berbagai permasalahan tersebut untuk proses produksi pada roasting yang masih manual dan sederhana diperlukan peralatan yang didukung dengan teknologi mesin yaitu mesin roasting. Fungsi mesin tersebut yaitu menjaga aroma dan rasa dari kopi serta warna kopi akan merata sempurna sesuai dengan proses pengolahan roasting yang diinginkan. Penyimpanan produk kopi yang belum diperhatikan dengan menyediakan peralatan berupa satu unit etalase kaca, sehingga hasil produk dapat disimpan dalam etalase, higienitasnya dapat terjamin dan image konsumen dapat terjaga terhadap hasil produk kopi. Hasil yang diperoleh setelah menggunakan mesin roasting modern tersebut yaitu adanya efisiensi waktu dan tenaga. Mesin roasting modern tersebut hanya membutuhkan tenaga 1 orang untuk meroast dan mendinginkan kopi. Pekerjaan tersebut juga bisa dilakukan sambil mengerjakan pekerjaan lainnya. Etalase yang terlah tersedia membantu penataan kopi yang siap untuk dijual atau dipasarkan sehingga higienitas kopi terjamin.
\end{abstract}

Kata kunci: roasting kopi, proses roasting

\section{Abstract}

The Production Process of Roasting KSM Galuh Lestari Arabica coffee is still manual with simple equipment in the form of a drum tube. The results of the manual roasting process are uneven in the level of ripeness and color of the coffee, it requires a long time and a very high level of care in the coffee roasting process. Inadequate storage of coffee products. The solution to these various problems for the production process for roasting which is still manual and simple requires equipment that is supported by machine technology, namely roasting machines. The function of this machine is to maintain the aroma and taste of the coffee and the color of the coffee to be perfectly even according to the desired roasting processing process. Storage of coffee products that have not been considered by providing equipment in the form of a glass storefront unit, so that the product can be stored in a storefront, hygiene can be guaranteed and consumer image can be maintained on the results of coffee products. The results obtained after using this modern roasting machine are the efficiency of time and energy. This modern roasting machine only requires 1 person to roast and cool coffee. This work can also be done while doing other work. The storefronts that are readily available help organize the coffee that is ready to be sold or marketed so that coffee hygiene is guaranteed.

Keywords: coffee roasting, roasting process

Copyright (c) 2020 Ria Manurung, Oskar Ika Adi Nugroho, Eko Apriliyanto

$\triangle$ Corresponding author

Address : Sekolah Tinggi Ilmu Komputer Yos Sudarso

Email : ria.manurung@stikomyos.ac.id

ISSN 2721- 9224 (Media Cetak)

Phone : 081262040634

ISSN 2721- 9216 (Media Online)

DOI : https://doi.org/10.31004/abdidas.v1i5.102 


\section{PENDAHULUAN}

Masyarakat Dusun Gunungmalang Desa Serang Kecamatan Karangreja Kabupaten Purbalingga telah memulai pertanian kopi sejak lebih dari 10 tahun yang lalu. Masyarakat sekitar Dusun Gunungmalang pada waktu itu belum begitu memahami manfaat dan fungsi kopi dengan baik sehingga kurang memberi dampak terhadap kesejahteraan ekonomi masyarakat sekitar Gunungmalang. Seiring dengan berjalannya waktu dan berkembangnya teknologi, masyarakat sekitar Gunungmalang membentuk kelompok petani kopi dengan nama Kelompok Swadaya Masyarakat (KSM) Galuh Lestari yang diketuai oleh Bapak Suyatno Karsum. Kelompok tersebut melakukan pengolahan kopi dari awal proses sampai dengan proses kopi siap dijual. Beberapa jenis kopi yang diproduksi oleh kelompok ini, seperti jenis kopi natural, wine, honey serta full washed. Proses pengolahan buah kopi yang baru dipanen sampai menjadi bubuk kopi yang tinggal diseduh sangat memerlukan waktu yang panjang apalagi jika proses tersebut dilakukan secara manual. Pengolahannya membutuhkan tenaga yang besar, waktu yang lama dan rasa yang diperoleh dari biji kopi belum tentu berkualitas baik.

KSM Galuh Lestari pada awalnya melakukan semua proses pengolahan kopi secara manual, namun seiring dengan kesadaran KSM Galuh Lestari untuk memajukan kelompok tersebut, beberapa mesin peralatan proses pengolahan kopi dapat dibeli dan digunakan seperti mesin pulper untuk mengupas kulit basah kopi dan teknologi mesin huller untuk mengupas kulit kering kopi. Proses menyangrai biji kopi dapat dilakukan dengan dua cara yakni secara tradisional dan menggunakan teknologi penyangrai biji kopi (Setyawan et al., 2019). Teknologi penyangrai kopi atau sering disebut mesin roasting kopi merupakan suatu alat yang diciptakan untuk mengolah biji kopi dari biji kopi masih berbentuk green bean atau biji kopi yang masih mentah menjadi biji kopi dalam bentuk roast bean atau biji kopi yang sudah matang dan siap diolah untuk dipasarkan (Biorefinery, 2018).

Permasalahan mitra KSM Galuh Lestari yaitu proses produksi roasting kopi Arabika yang masih manual dengan peralatan sederhana berupa tabung drum. Hasil dari proses roasting secara manual tersebut tidak merata tingkat kematangan dan warna kopinya, membutuhkan waktu yang lama dan tingkat kehati-hatian yang sangat tinggi dalam proses roasting kopi produksinya. Permasalahan yang kedua yaitu penyimpanan produk kopi belum diperhatikan.

Solusi dari berbagai permasalahan tersebut yaitu untuk proses produksi pada roasting yang masih manual dan sederhana diperlukan peralatan yang didukung dengan teknologi mesin yaitu mesin roasting. Solusi untuk penyimpanan produk kopi yang belum diperhatikan yaitu menyediakan peralatan berupa satu unit etalase kaca, sehingga hasil produk dapat disimpan dalam etalase, higienitasnya dapat terjamin dan image konsumen dapat terjaga terhadap hasil produk kopi. Penelitian yang dilakukan oleh (Batubara et al., 2019) menyatakan bahwa mesin penyangrai kopi adalah mesin yang berfungsi untuk menyangrai biji kopi menjadi biji kopi matang yang siap untuk dikonsumsi. Mesin penyangrai kopi memiliki 
beberapa keunggulan diantaranya adalah efisiensi waktu dan tenaga. Seiring dengan perkembangan teknologi saat ini maka cara menyangrai kopi secara tradisional sudah mulai banyak ditinggalkan.

Penelitian yang dilakukan (Kurniawan \& Hastuti, 2017) dengan judul "Penentuan Kualitas Biji Kopi Arabika Dengan Menggunakan Analytical Hierarchy Process (Studi Kasus Pada Perkebunan Kopi Lereng Gunung Kelir Jambu Semarang)", menyimpulkan bahwa aplikasi dengan menggunakan metode AHP (Analytical Heirarchy Process) dapat menentukan kualitas biji kopi dengan input kadar air, cacat biji, dan ketinggian lahan. Penelitian berikutnya dilakukan oleh (K. Pradipta \& K. Fibrianto, 2017) dengan judul "Jurnal Review Perbedaan Air Seduh Terhadap Persepsi Multisensoris Kopi”. Penelitian ini memberikan kesimpulan bahwa kopi yang berkualitas ditentukan dari aroma, rasa dan flavor. Aroma, rasa dan flavor adalah bagian dari persepsi multisensoris pada manusia. Faktor varietas dan kualitas biji kopi, lama dan suhu penyangraian, kondisi penyimpanan, proses grinding, teknik penyeduhan dan air seduhnya sangat menentukan aroma, rasa dan flavor pada kopi.

Tujuan dilakukannya pengabdian ini supaya dapat menghasilkan kopi yang berkualitas baik aroma khas, rasa yang nikmat, dan tingkat kafein yang seimbang dengan kadar keasamannya sehingga dapat meningkatkan minat para pencinta kopi yang tentu saja akan berdampak terhadap omzet KSM Galuh Lestari Gunungmalang.

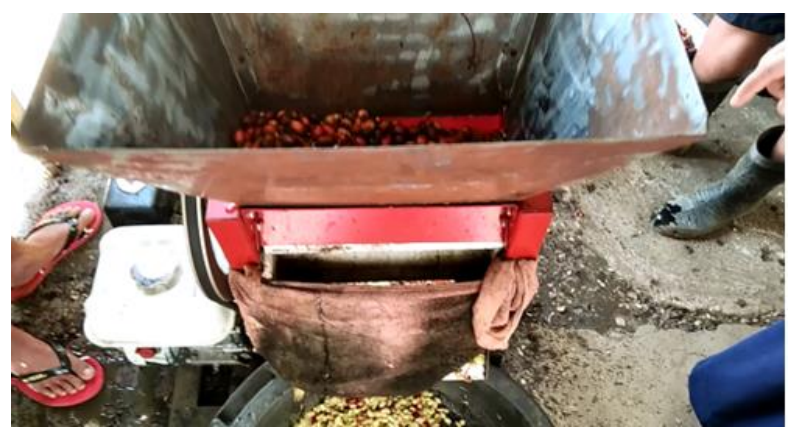

Gambar 1. Mesin Pulper Mengupas Kulit Kopi yang Baru Dipanen

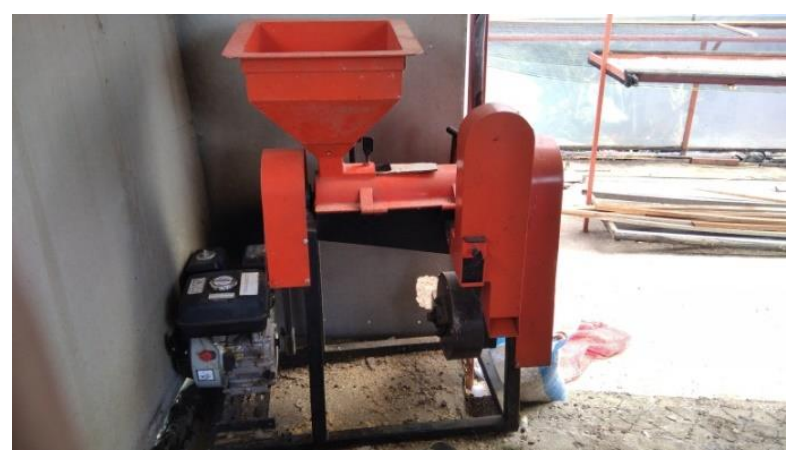

Gambar 2. Mesin Huller untuk Mengupas Kulit Kering pada Kopi yang Sudah Dikeringkan

KSM Galuh Lestari masih menggunakan mesin manual untuk menyangrai kopi. Rasa, aroma dan kafein pada kopi sangat dipengaruhi oleh proses roasting atau menyangrai (Zarwinda \& Sartika, 2019).

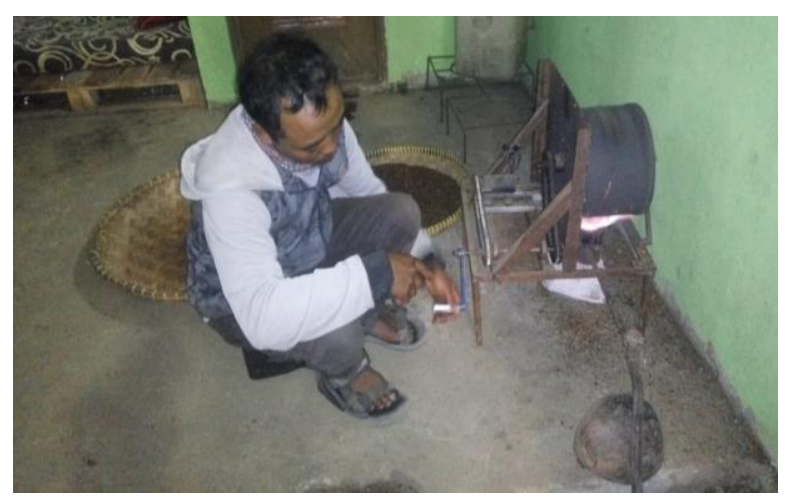

Gambar 3. Mesin Roasting Manual 


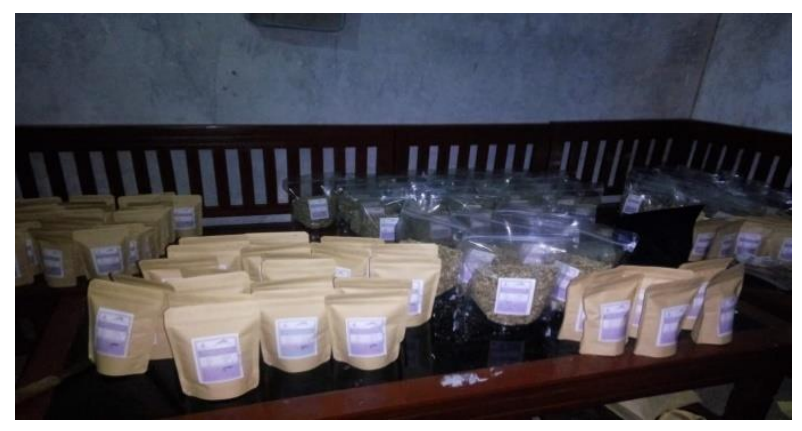

Gambar 4. Penataan Kopi Hasil Produksi yang Belum Memadai

\section{METODE}

1. Permasalahan dalam bidang produksi dengan menyediakan peralatan mesin roasting untuk membantu proses produksi roasting pada kopi Arabika (Batubara et al., 2019). Prinsip kerja dari alat roasting tersebut sebagai berikut:

a. Produk dipanaskan dengan suhu yang terkontrol secara otomatis dalam mesin.

b. Selama pemanasan tersebut, alat ini terus berputar hingga suhu merata.

c. Suhu yang merata akan membuat tekanan pada biji kopi sehingga dapat matang dengan sempurna sesuai dengan keinginan mitra dan permintaan pasar (Sasongko \& Rivai, 2018).

Tim PKM juga akan melakukan pelatihan untuk penggunaan peralatan mesin roasting dan pengoperasian peralatan produksi roasting. Pelatihan diberikan dalam bentuk demonstrasi tentang pengoperasian peralatan oleh Tim kepada mitra dan dilanjutkan dengan praktek oleh peserta KSM Galuh Lestari sampai mitra KSM mampu mengoperasikan peralatan tersebut, demikian juga halnya untuk pemeliharaan peralatan mesin tersebut. Pelatihan ini bertujuan agar mitra KSM mampu meningkatkan kinerja proses produksinya dengan menggunakan prasarana peralatan produksi yang didukung dengan teknologi.
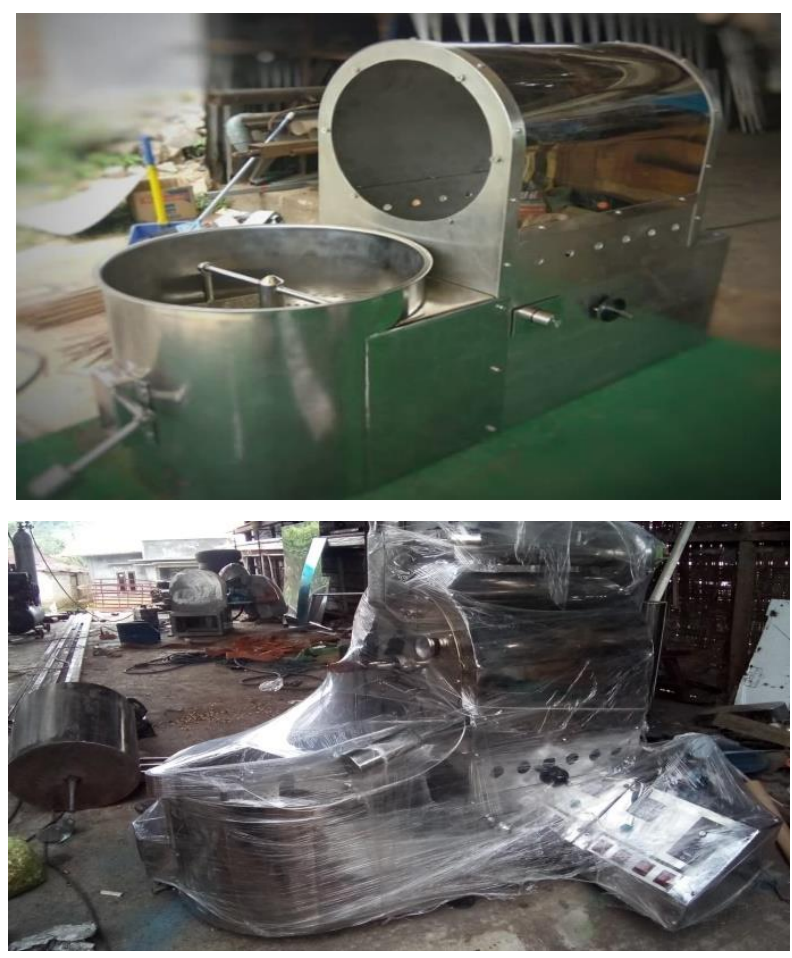

Gambar 5. Proses Pembuatan Mesin Roasting Kopi

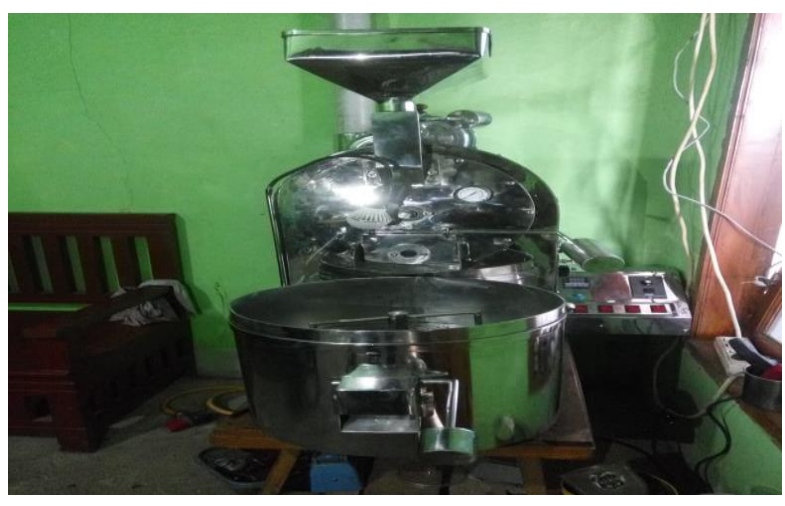

Gambar 6. Mesin Roasting Modern dengan Teknologi Siap Digunakan

2. Penyimpanan produk kopi dilakukan dengan menempatkan satu set etalase kaca untuk penyimpanan hasil produksi kopi. Penataan hasil produksi ini diharapkan mampu 
mendukung kelancaran proses produksi dan memberi image positif bagi customer mitra KSM dan juga higienitas dari produk kopi tersebut.

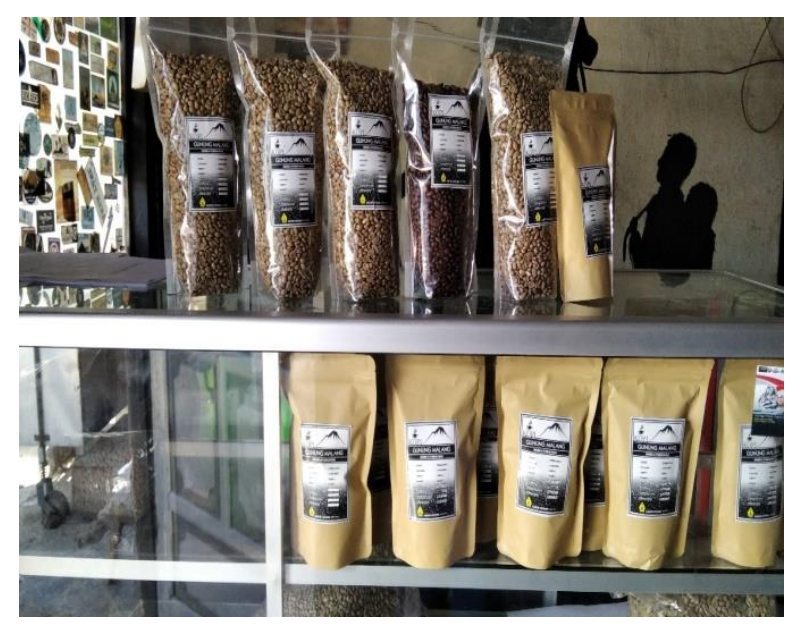

Gambar 7. Etalase Penyimpanan Produk Kopi Siap Dijual-Dipasarkan

\section{HASIL DAN PEMBAHASAN}

\section{Mesin Roasting}

a. Rata-rata banyaknya kopi yang dapat diroasting dengan alat roasting manual (sebelum menggunakan Mesin Roasting Modern).

Untuk me-roasting kopi sebanyak $5 \mathrm{~kg}$ dalam sehari, KSM Galuh Lestari Gunungmalang membutuhkan waktu selama 225 menit atau setara dengan 3 jam 45 menit dengan tenaga tangan 1 orang yang digunakan untuk memutar tabung pada alat roasting manual dengan tingkat pekerjaan tergolong berat dan penuh kehati-hatian, dan 1 orang tenaga tangan dibantu kipas angin untuk mendinginkan kopi hasil roasting dengan durasi waktu sekitar 30 menit per $1 \mathrm{~kg}$.

Tabel 1. Hasil Menggunakan Mesin Manual

\begin{tabular}{|l|l|l|l|l|}
\hline $\begin{array}{l}\text { Lama } \\
\text { waktu } \\
\begin{array}{l}\text { Me- } \\
\text { roasting }\end{array}\end{array}$ & $\begin{array}{l}\text { Banyak } \\
\text { nya max. } \\
\text { kopi } \\
\mathrm{kg})\end{array}$ & $\begin{array}{l}\text { Kemampuan } \\
\text { tenaga untuk } \\
\text { me-roasting }\end{array}$ & $\begin{array}{l}\text { Total } \\
\text { kopi } \\
\text { yang } \\
\text { sudah } \\
\text { diroast }\end{array}$ & $\begin{array}{l}\text { Total } \\
\text { Lama } \\
\text { Waktu }\end{array}$ \\
\hline $\begin{array}{l}45 \\
\text { menit }\end{array}$ & $1 \mathrm{~kg}$ & 5 kali / hari & $5 \mathrm{~kg}$ & $\begin{array}{l}225 \\
\text { menit }\end{array}$ \\
\hline
\end{tabular}

b. Rata-rata hasil kopi yang sudah diroasting sesudah menggunakan mesin roasting modern.

Untuk me-roasting kopi sebanyak $5 \mathrm{~kg}$ hanya membutuhkan waktu sebanyak 20 menit dan langsung dapat didinginkan pada mesin roasting tersebut dengan durasi waktu 20 menit per $5 \mathrm{~kg}$. Tenaga manusia yg dibutuhkan hanya 1 orang dengan tingkat pekerjaan tergolong ringan. Mesin roasting modern dapat meroast kopi dan juga sekaligus mendinginkan kopi hasil roast. Kualitas kopi yang dihasilkan terjamin dan layak bersaing dengan kopi hasil produksi petani lainnya.

Tabel 2. Hasil Menggunakan Mesin Roasting Modern

\begin{tabular}{|l|l|l|}
\hline $\begin{array}{l}\text { Lama waktu } \\
\text { Me-roasting }\end{array}$ & $\begin{array}{l}\text { Banyak nya } \\
\text { max. kopi (kg) }\end{array}$ & $\begin{array}{l}\text { Kemampuan mesin } \\
\text { untuk me-roasting }\end{array}$ \\
\hline 20 menit & $5 \mathrm{~kg}$ & Tidak ada batasan \\
\hline
\end{tabular}

Hasil yang diperoleh setelah menggunakan mesin roasting modern tersebut sejalan dengan pendapat dari peneliti sebelumnya yaitu (Batubara et al., 2019) yang menyatakan bahwa keunggulan dari mesin penyangrai kopi yaitu efisiensi waktu dan tenaga. Mesin roasting modern tersebut hanya membutuhkan tenaga 1 orang untuk meroast dan mendinginkan kopi. Pekerjaan tersebut juga bisa dilakukan sambil mengerjakan pekerjaan lainnya. 


\section{Penyuluhan dan Pelatihan}

Berkaitan dengan peningkatan keterampilan para anggota KSM Galuh Lestari dalam hal teknik pengelolaan kopi yaitu dengan cara penyuluhan dan pelatihan. Tahapan kegiatn yang dilakukan adalah :

1. Penyuluhan tentang bagaimana agar rasa kopi tetap terjaga dengan baik kepada para anggota KSM Galuh Lestari. Tim PKM berperan sebagai fasilitator sedangkan mitra berpartisipasi sebagai objek penyuluhan.

2. Pelatihan menggunakan mesin roasting kopi modern. Tim PKM berperan sebagai fasilitator sedangkan mitra berpartisipasi sebagai objek penyuluhan.

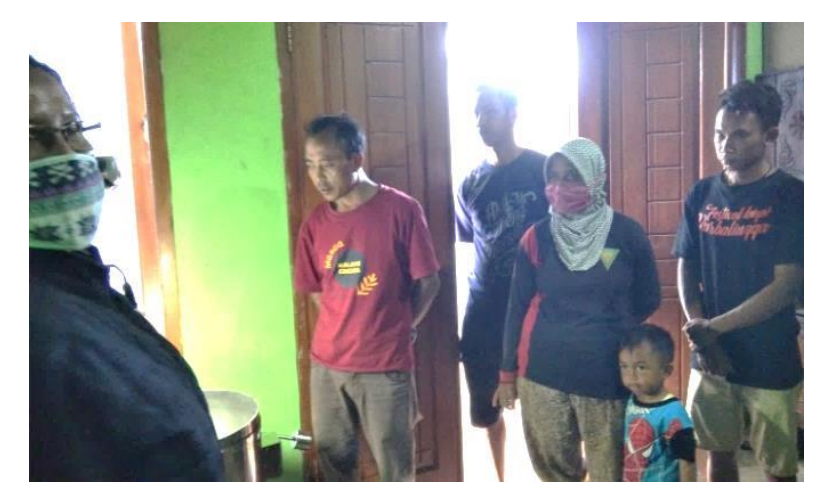

Gambar 9.Pelatihan menggunakan Mesin Roasting Modern oleh Tim PKM Kepada Anggota KSM Galuh Lestari

\section{SIMPULAN}

Hasil yang diperoleh setelah menggunakan mesin roasting modern tersebut yaitu adanya efisiensi waktu dan tenaga. Mesin roasting modern tersebut hanya membutuhkan tenaga 1 orang untuk meroast dan mendinginkan kopi. Pekerjaan tersebut juga bisa dilakukan sambil mengerjakan pekerjaan lainnya. Etalase yang terlah tersedia membantu penataan kopi yang siap untuk dijual atau dipasarkan sehingga higienitas kopi terjamin. Pelaksanaan kegiatan PKM ini diharapkan dapat bermanfaat dan membantu petani kopi Dusun Gunungmalang melalui KSM Galuh Lestari dan dapat mengembangkan daya saing kualitas kopi Gunungmalang sehingga dapat lebih dikenal oleh masyarakat luas tidak hanya oleh para penikmat kopi saja. Pelaksanaan kegiatan pengabdian masyarakat ini berjalan lancar sesuai dengan yang telah direncanakan. Tim pengabdian berharap hubungan antara mitra dan tim pengabdian dapat berlanjut di masa yang akan datang.

\section{UCAPAN TERIMAKASIH}

Terimakasih kepada RISTEK/ BRIN, LPPM STIKOM Yos Sudarso Purwokerto, Politeknik Banjarnegara dan KSM Galuh Lestari Gunungmalang.

\section{DAFTAR PUSTAKA}

Batubara, A., Widyasanti, A., \& Yusuf, A. (2019). Uji Kinerja dan Analisis Ekonomi Mesin Roasting Kopi (Studi Kasus di Taman Teknologi Pertanian Cikajang - Garut). Jurnal Teknotan, 13(1), 1. https://doi.org/10.24198/jt.vol13n1.1

Biorefinery, T. P. (2018). Biorefinery Kopi. Ppbb Itb, $1-51$.

K. Pradipta \& K. Fibrianto. (2017). JURNAL REVIEW PERBEDAAN AIR SEDUH TERHADAP PERSEPSI MULTISENSORIS KOPI Review Journal of Brewing Water Differences on Multisensory Perception of. $5(1), 85-91$.

Kurniawan, W. M., \& Hastuti, K. (2017). Penentuan Kualitas Biji Kopi Arabika Dengan Menggunakan Analytical Hierarchy Process (Studi Kasus Pada Perkebunan Kopi Lereng Gunung Kelir Jambu Semarang). 

Swadaya Masyarakat Galuh Lestari - Ria Manurung, Oskar Ika Adi Nugroho, Eko Apriliyanto DOI : https://doi.org/10.31004/abdidas.v1i5.102

Simetris : Jurnal Teknik Mesin, Elektro Dan

Ilmu Komputer, $8(2), \quad 519$.

https://doi.org/10.24176/simet.v8i2.1358

Sasongko, I. J., \& Rivai, M. (2018). Mesin

Pemanggang Biji Kopi dengan Suhu

Terkendali Menggunakan Arduino Due.

Jurnal Teknik ITS, 7(2).

https://doi.org/10.12962/j23373539.v7i2.312

05

Setyawan, E. Y., Widodo, B., Bahtiar, A. D. M., \& Faradisa, I. S. (2019). Peningkatan Produktivitas Mesin Sangrai Biji Kopi Di Ukm Kabupaten Kediri. Jurnal Aplikasi Dan Inovasi Ipteks "Soliditas" (J-Solid), 2(1), 19. https://doi.org/10.31328/js.v2i1.1284

Zarwinda, I., \& Sartika, D. (2019). Pengaruh Suhu Dan Waktu Ekstraksi Terhadap Kafein Dalam Kopi. Lantanida Journal, 6(2), 180. https://doi.org/10.22373/lj.v6i2.3811 